\title{
On Presentation of Optimal Treatment Plan in Radiotherapy of Parotid Cancer: A Comparison of Nine Techniques in Three Dimensional Conformal Radiation Therapy (3DCRT)
}

\author{
Ahad Zeinali, Farideh Farokhi Moghadam* \\ Medical Physics Department, Faculty of Medicine, Urmia University of Medical Sciences, Urmia, Iran \\ Email address: \\ f.farokhi93@gmail.com (F. F. Moghadam) \\ ${ }^{*}$ Corresponding author \\ To cite this article: \\ Ahad Zeinali, Farideh Farokhi Moghadam. On Presentation of Optimal Treatment Plan in Radiotherapy of Parotid Cancer: A Comparison of \\ Nine Techniques in Three Dimensional Conformal Radiation Therapy (3DCRT). International Journal of Medical Imaging. \\ Vol. 4, No. 4, 2016, pp. 32-38. doi: 10.11648/j.ijmi.20160404.12
}

Received: July 23, 2016; Accepted: August 3, 2016; Published: August 29, 2016

\begin{abstract}
Materials and Methods: CT of parotid patients during 2012 to 2014 is used. Twelve patients were evaluated by TPS Core plan, 3D dose distribution and using of dose-volume histogram (DVH), nine techniques were evaluated: a. 6MV photons, 3-fields AP (wedge), PA (wedge), lateral (open), b. unilateral $10 \mathrm{Mev}$ electrons, c. unilateral $14 \mathrm{Mev}$ electrons, d. Mixed beam technique using 6MV photon and $10 \mathrm{Mev}$ electron (1:4 weighting), e. Mixed beam technique using 6MV photon and $14 \mathrm{Mev}$ electron (1:4 weighting), f. unilateral $10 \mathrm{Mev}$ electrons with bolus ( $0.5 \mathrm{~cm}$ bolus is used), g. unilateral $14 \mathrm{Mev}$ electrons with bolus $(0.5 \mathrm{~cm}$ bolus is used), h. Mixed beam technique using $6 \mathrm{MV}$ photon and $10 \mathrm{Mev}$ electron (1:4 weighting) with Bolus ( $0.5 \mathrm{~cm}$ bolus is used), i. Mixed beam technique using $6 \mathrm{MV}$ photon and $14 \mathrm{Mev}$ electron (1:4 weighting) with Bolus ( $0.5 \mathrm{~cm}$ bolus is used) Results: Using of DVH to appraise, the dose to OARs are 0 for techniques 6MV photons, (3-fields), unilateral $10 \mathrm{Mev}$ electrons with and without Bolus, unilateral $14 \mathrm{Mev}$ electrons with \& without Bolus. The highest conformal and homogeneity index and near to 1 were for $6 \mathrm{MV}$ photons, 3-fields, unilateral $14 \mathrm{Mev}$ electrons with and without Bolus, mixed beam technique using 6MV photon and $14 \mathrm{Mev}$ electron with and without Bolus.
\end{abstract}

Keywords: Bolus, Parotid Gland Cancer, Dose Volume Histogram,

Three Dimensional Conformal Radiation Therapy (3DCRT)

\section{Introduction}

Malignant salivary gland tumors compromise about 3 to $5 \%$ in the head and neck cancer [1-3]. Parotid tumors are the largest salivary gland tumors [1-3]. Today, radiotherapy combined with surgery in the treatment of parotid tumors widely are used specially for high grade parotid tumors [4-6].

One of concern and challenge issue of radiotherapy is that the treatment of these tumors with irregular surface due to the presence of external ear and region of different physical electron density (air cavities, dense bone, soft tissue) [7-10]. Existing of the heterogeneous tissues, internal inhomogeneity and also the diverse external contour yield an inhomogeneous dose distribution. Therefore some of the consequences of a heterogeneous treatment volume led to under dos of tumor (target volume) and over dose of critical structures [7-10].
Some of side-effects of radiotherapy to parotid tumors are osteoradionecrosis of the mandible, temporal lobe necrosis, Xerostomia, sensorineural hearing loss [3, 8, 9, 13, 28, 29].

Recent developments in three dimensional computerized radiation treatment planning (3D RTP) systems led to effective treatment with low side effects in organ at risks by using accurate calculation of dose distribution and optimal treatment has helped $[8,11,12]$. The information included a $3 \mathrm{D}$ dose distribution is condensed into dose-volume histograms (DVHs) which are essentially graphical demonstration of dose distributions exactly the target volume and organ at risk [8, 11, 12].

Two basic technique of radiotherapy such as a pair of angled wedged photon beams and mixed beam of photons 
and electrons with different weighting are used [8]. The minimum treatment volume includes the ipsilateral parotid bed and the upper neck nodes $[8,13]$. Using of bolus is other method which is used in radiotherapy of these tumors [1418]. Bolus is a tissue-equivalent material that is widely used in electron and photon radiation therapy to move or shift the buildup region $[19,20]$.

According to the recommendations of AAPM Task Group 25 (American Association of Physicists in Medicine), bolus should designed in such a way that target Volume received at least 90 percent of prescribed doses but with internal inhomogeneity of tumor surface and non-uniformity of the dose with bolus observed that it would be the treatment of tumors of the parotid challengeable [15, 18, 19, 21-27].

Despite reports of many researchers who study mainly different treatment techniques and use of various radiation source (photons, electrons and a mixed beam) for this type of tumors, no unified study looking at impact of bolus in achieving an optimal treatment for parotid tumors $[15,18$, 19, 21, 22, 24, 27, 30, 31].

Therefore offering an optimal treatment plan to the desired results in terms of dose distribution factors to adequate target coverage and protect critical structures surrounding OARs is so important.

This study aimed to achieve an optimal treatment plan using low-energy electrons, as well as different modes of electrons and photons will be considered. Also the effect of bolus to achieve the optimal treatment plan is performed.

\section{Methods}

The computed tomography (CT) scans of parotid patients were used in this study during 2012 to 2014 . The prescription depth was $4.5 \mathrm{~cm}$. These parameters were evaluated base on 12 patients who were referred to Omid hospital at Oncology Department in Urmia city. These patients previously treated postoperatively in Omid institution. All patients were treated using individual thermoplastic mask immobilization head and shoulder fixation and the CT images are taken by CTsimulator 2 slices. The CT data were transferred to CorePlan treatment planning system (ETAR). The included criterion in this study are uninvolved skin, any history about previously treated with radiotherapy and also there aren't any extracapsular nodal spread.

Target volumes such as planning target volume (PTV) and gross tumor volume (GTV) and organs at risk (OARs) such as spinal cord, contralateral parotid gland and temporal mandibular joint (TMJ) were contoured on the CT images and dose prescription were performed according to the International Commission on Radiation Units (ICRU) 62 guidelines. For each patient, nine plans were done. The beam energies of each plan and field arrangements are listed in Table 1.

For each technique, the dose distribution was optimized to obtain uniform dose coverage to a prescription depth of 4.5 $\mathrm{cm}$. A isodose distribution for a $6 \mathrm{MV}$ wedge pair technique 1 is shown in figure 1 . The dose volume histograms (DVH) were generated for target volume and OARS.

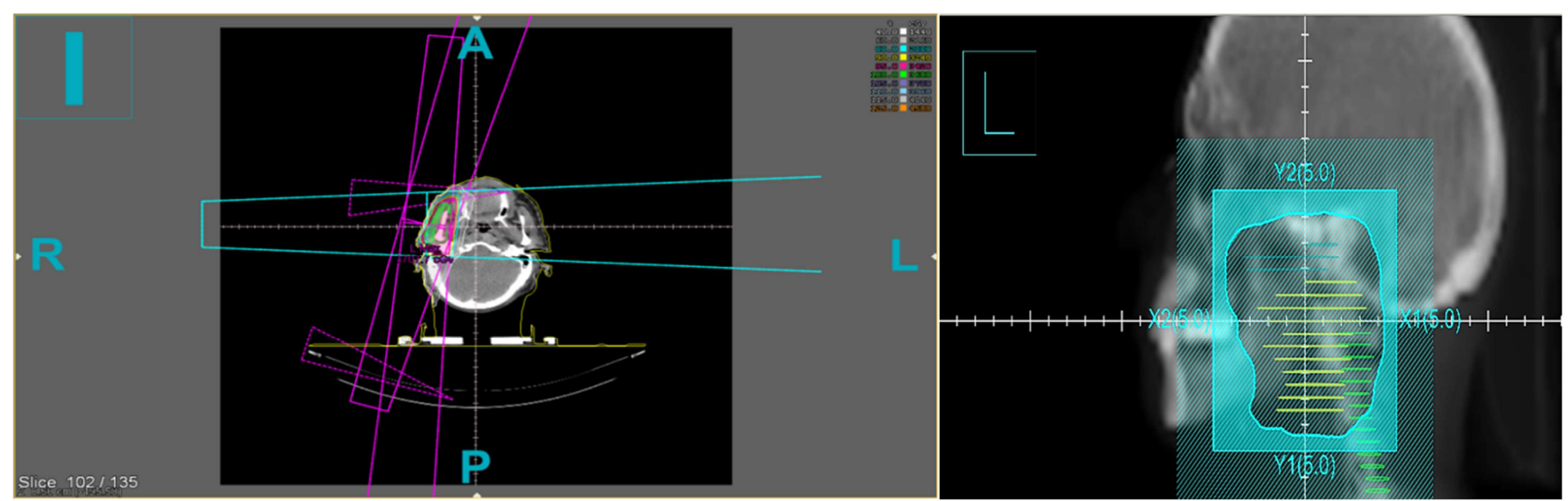

Fig. 1. (a). A isodose distribution for a plan 1, standard 6MV wedge pair technique. (b) DRR image.

The comparison of each plan depends on dose 5\%, 95\% coverage of PTV, sparing of OARS dose conformity index (CI), dose homogeneity within PTV by homogeneity index (HI). HI and CI were measured by using the equation 1, 2:

$$
\begin{aligned}
& \frac{\text { Volume within } 95 \% \text { isodose line }}{\text { Volume of PTV }}=C I \\
& \frac{D 5 \%}{D 95 \%}=H I
\end{aligned}
$$

HI measures the dose homogeneity across the PTV. Where D5\% is the dose covered by $5 \%$ of the target volume, D95\% is the dose covered by $95 \%$ of the target volume.

Sparing of OARs was assessed using the mean dose for contralateral parotid, spinal cord, TMJ (temporomandibular joint) and they also were compared. 
Table 1. All of scenarios, treatment techniques considered for each patient in this study.

\begin{tabular}{|c|c|c|c|}
\hline Technique & Beam energies & Beam arrangement & Beam weights \\
\hline 1. & 6MV Photon & $\mathrm{AP} / \mathrm{PA} / \mathrm{Lat}$ & $\begin{array}{l}\mathrm{AP}\left(40 \%, 30^{\circ} \mathrm{W}\right), \mathrm{PA}\left(40 \%, 30^{\circ} \mathrm{W}\right) \text {, } \\
\text { Lat. }(20 \% \text {, open })\end{array}$ \\
\hline 2. & 10Mev Electron & Lateral & $100 \%$ \\
\hline 3. & 14Mev Electron & Lateral & $100 \%$ \\
\hline 4. & $6 \mathrm{MV}$ Photon+ $10 \mathrm{Mev}$ Electron & AP/PA (Photon)+lateral (electron) & $\begin{array}{l}\text { AP }\left(40 \%, 30^{\circ} \mathrm{W}\right), \mathrm{PA}\left(40 \%, 30^{\circ} \mathrm{W}\right) \text {, } \\
\text { Lat. }(20 \% \text {, open })\end{array}$ \\
\hline 5. & $6 \mathrm{MV}$ Photon+ $14 \mathrm{Mev}$ Electron & AP/PA (Photon)+lateral (electron) & $\begin{array}{l}\text { AP }\left(40 \%, 30^{\circ} \mathrm{W}\right), \mathrm{PA}\left(40 \%, 30^{\circ} \mathrm{W}\right) \text {, } \\
\text { Lat. }(20 \% \text {, open })\end{array}$ \\
\hline 6. & $10 \mathrm{Mev}$ Electron $+0.5 \mathrm{~cm}$ Bolus & Lateral & $100 \%$ \\
\hline 7. & $14 \mathrm{Mev}$ Electron $+0.5 \mathrm{~cm}$ Bolus & Lateral & $100 \%$ \\
\hline 8. & $6 \mathrm{MV}$ Photon+ $10 \mathrm{Mev}$ Electron $+0.5 \mathrm{~cm}$ Bolus & AP/PA (Photon)+lateral (electron) & $\begin{array}{l}\text { AP }\left(40 \%, 30^{\circ} \mathrm{W}\right), \mathrm{PA}\left(40 \%, 30^{\circ} \mathrm{W}\right) \text {, } \\
\text { Lat. }(20 \% \text {, open })\end{array}$ \\
\hline 9. & $6 \mathrm{MV}$ Photon+14 Mev Electron+ $0.5 \mathrm{~cm}$ Bolus & AP/PA (Photon)+lateral (electron) & $\begin{array}{l}\text { AP }\left(40 \%, 30^{\circ} \mathrm{W}\right), \mathrm{PA}\left(40 \%, 30^{\circ} \mathrm{W}\right) \text {, } \\
\text { Lat. }(20 \% \text {, open })\end{array}$ \\
\hline
\end{tabular}

\section{Statistical analysis}

For all patients, $\mathrm{HI}$ and CI were calculated. When the CI was almost 1 indicates the plan is more conformal. HI value near to 1 number indicates a more homogenous dose distribution. Analyzed statistically using excel sheet 2016 and SPSS ANOVA and a post Hoc Tukey test was performed for individual comparison.

\section{Result}

The HI and CI were calculated for PTV for each technique (Table 2). Comparing of nine techniques help us to find an optimal technique.

Table 2 and 3 gives the statistical analysis for homogeneity and conformity of PTV according to Tukey test (table 2, 3 . Figure 2). The results of HI divide to 4 groups and the results of each group are similar and different with other group. The number 1 for table of HI shown the highest homogeneity and also photon $6+$ electron $14+$ bolus, photon $6+$ electron 14 , electron 14, electron 14+ bolus, photon 6 are similar together with $95 \%$ confidence level (table 2). For CI, two groups are made and each group is different with other group. The number 2 for table 3 had that the highest conformity. The members of number 2 include electron $14+$ bolus, photon $6+$ electron 14 , electron 14 , photon 6 , photon $6+$ electron $14+$ bolus and these members had similar conformity index.

Table 2. Homo index for nine plans.

\begin{tabular}{|c|c|c|c|c|}
\hline \multicolumn{5}{|c|}{ HI for each technique, $P$ value $<0.05$ and less than 0.001} \\
\hline \multirow{2}{*}{ Plan } & \multicolumn{4}{|c|}{ Subset for alpha $=0.05$} \\
\hline & 1 & 2 & 3 & 4 \\
\hline photon $6+$ electron $14+$ bolus & 1.0208 & & & \\
\hline photon $6+$ electron 14 & 1.0283 & & & \\
\hline electron 14 & 1.0325 & & & \\
\hline electron $14+$ bolus & 1.0367 & & & \\
\hline photon 6 & 1.0375 & & & \\
\hline photon $6+$ electron $10+$ bolus & & 1.1875 & & \\
\hline photon $6+$ electron 10 & & 1.2417 & 1.2417 & \\
\hline electron 10 & & & 1.2717 & \\
\hline electron $10+$ bolus & & & 1.3050 & 1.3050 \\
\hline Sig. & 1.000 & .532 & .151 & .055 \\
\hline
\end{tabular}

Table 3. Conformity index for nine plans.

\begin{tabular}{|c|c|c|}
\hline \multicolumn{3}{|c|}{ Conformity index for each plan, $P$ value less than 0.001} \\
\hline \multicolumn{3}{|c|}{ CI } \\
\hline \multicolumn{3}{|l|}{ Tukey HSD ${ }^{\mathrm{a}}$} \\
\hline \multirow{2}{*}{ Plan } & \multicolumn{2}{|c|}{ Subset for alpha $=0.05$} \\
\hline & 1 & 2 \\
\hline electron 10+bolus & .7342 & \\
\hline photon $6+$ electron $10+$ bolus & .7442 & \\
\hline photon $6+$ electron 10 & .7467 & \\
\hline electron 10 & 7492 & \\
\hline electron $14+$ bolus & & 9267 \\
\hline photon $6+$ electron 14 & & .9508 \\
\hline electron 14 & & .9517 \\
\hline photon 6 & & 9558 \\
\hline photon $6+$ electron $14+$ bolus & & 9617 \\
\hline Sig. & .996 & .310 \\
\hline \multicolumn{3}{|c|}{$\begin{array}{l}\text { Means for groups in homogeneous subsets are displayed. } \\
\text { a. Uses Harmonic Mean Sample Size }=12.000 \text {. }\end{array}$} \\
\hline
\end{tabular}
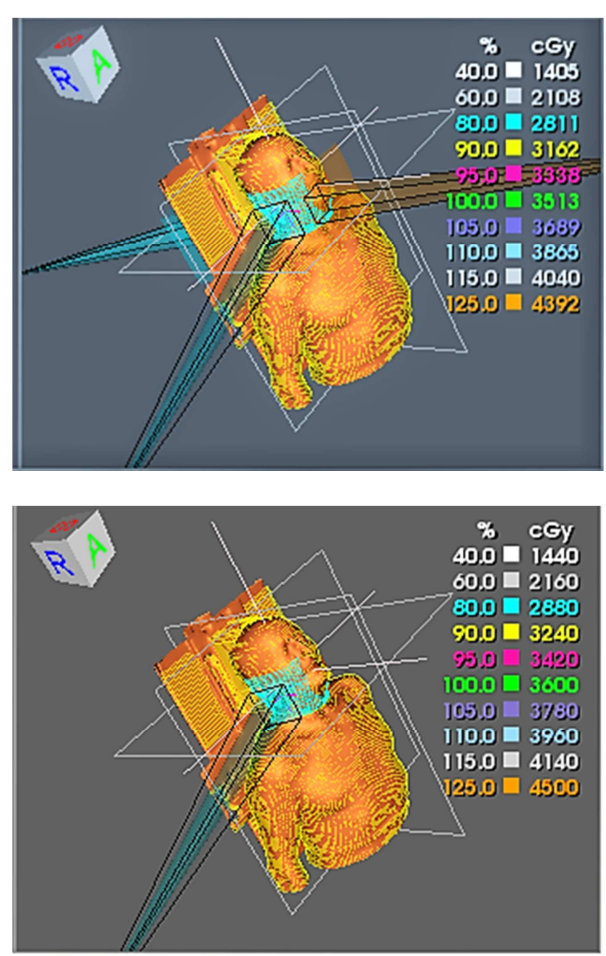

Fig. 2. Dose coverage of PTV by Bolus. 
A: for 8, 9 techniques, Mixed electron-photon beam with bolus, photon beam (1 technique).

B: for ipsilateral electron beam with bolus $(6,7$ technique).

Based on DVH and comparing of each plan by this curve, it is clear that single $6 \mathrm{MV}$ photon with 3 fields significantly can better coverage the PTV and spare OARs (fig. 3). The conformity index is. 9558 and it is similar to electron $14 \mathrm{Mev}$ with or without bolus and also the homogeneity index for single 6MV photon is 1.0375 . For coverage of PTV using by homogeneity and conformity index, the techniques of $1,3,5$, 7, 9 are similar and can obtain the best conformity and homogeneity at target volume, but by using the $\mathrm{DVH}$, the 1 , 3, 7 techniques can spare the OARs (fig. 3).
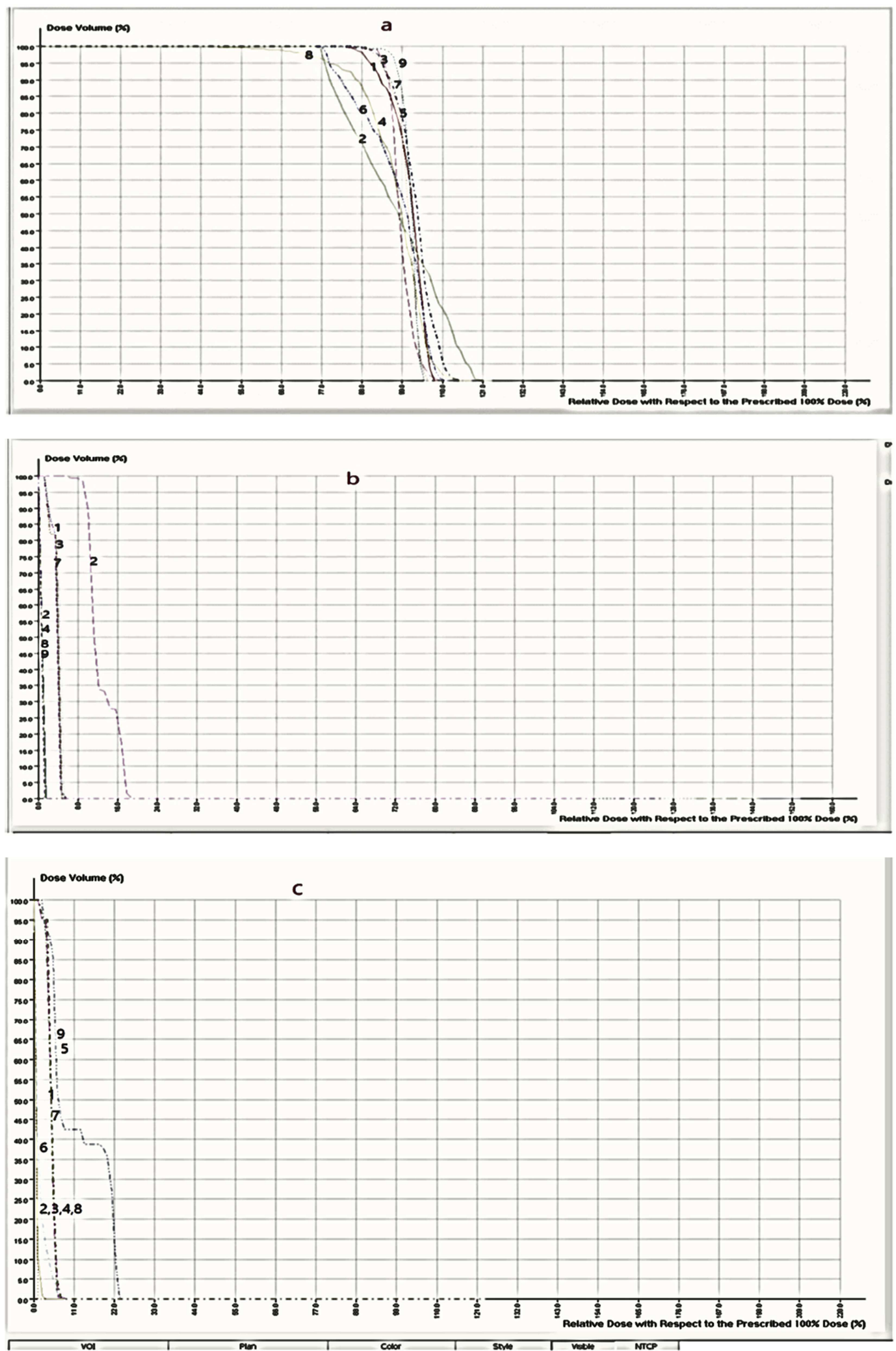


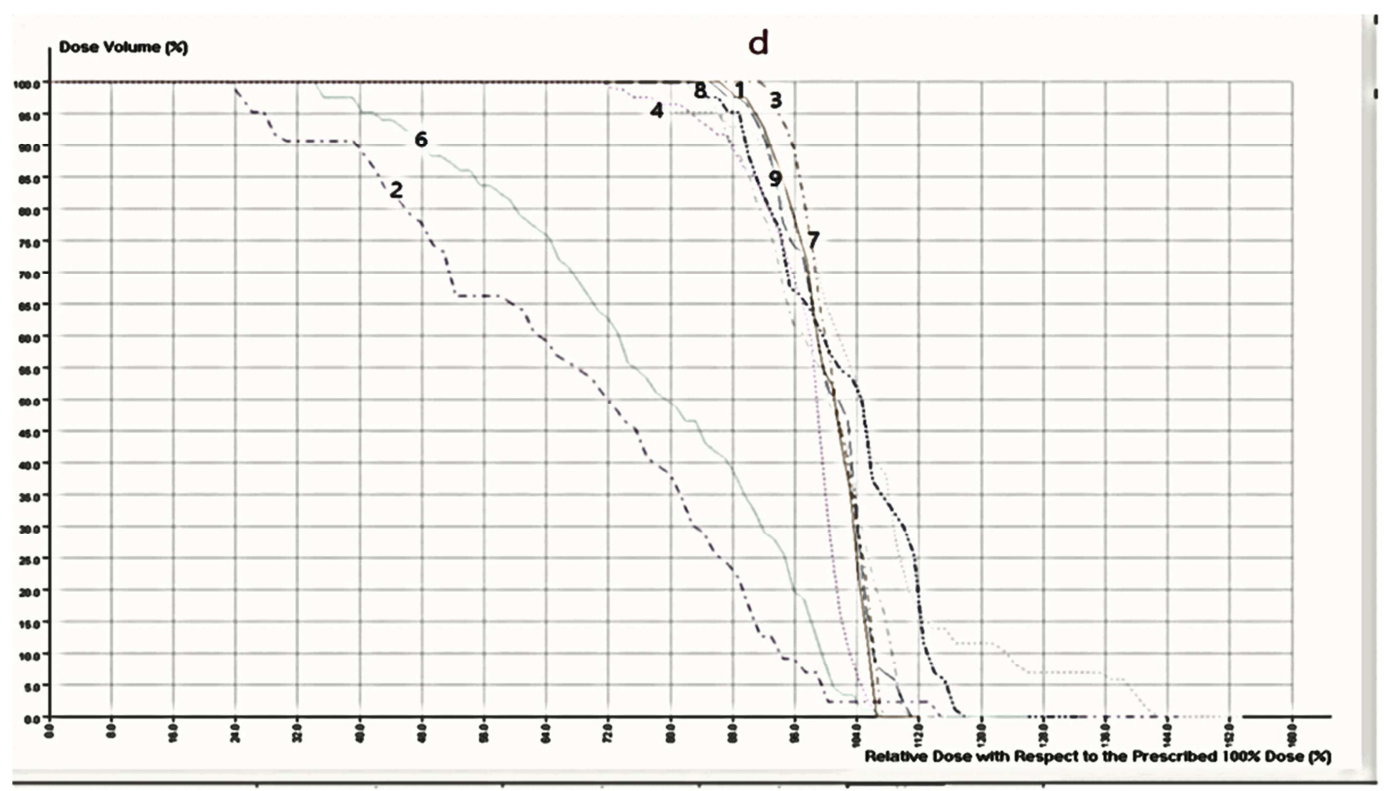

Fig. 3. Dose volume histogram for PTV (a), contralateral parotid (b), spinal cord (c), TM. Joint (d) for a patient with parotid cancer by nine different technique and dose is in percentage.

\section{Discussion}

Using of different techniques, beam energy could be used to achieve the optimal treatment plan. The characteristic of effective treatment planning are the good distribution dose, best coverage of PTV (planning target volume) and reducing dose to OARs organ $[8,32]$. This provides the best control of tumor, sparing of the surrounding OARs and highest life quality for patient of parotid cancer. In the current study, nine techniques are compared and the resulting of isodose distribution of the plan and DVH curve showed different coverage of PTV and OARs, homogeneity, conformity. Plan of numbers 1, 3, 5, 7 and 9 had the highest CI \& HI. They were achieved the good isodose distribution and coverage of PTV, but for sparing of OARs, the high energy electron was good (plan of 3,7) and also the 3-field photon was achieved best coverage of PTV and sparing of OARs (spinal cord, opposed parotid) expect temporal lobe (TM. Joint), the joint of temporal was necrosis due to excess dose to TMJ (higher than $45 \mathrm{~Gy}$ ). These results are in agreement with resulting of Yaparpalvi et al's and Hela et al's, but at their study the conformity index and homogeneity index did not achieved $[8,32]$. At Hela et al's study for photon technique, regarding OARs, contralateral parotid mean dose was 0.4 Gy which a little lower than mean dose in our study 0.6 Gy and also our resulting lower than the mean dose in study done by Nutting et al (1.6 Gy) (both used wedge pair technique, but at 2 field) $[8,32,33]$, due to different beam weighting and difference at incidence beam or perhaps due to difference of depth prescription dose. Also for spinal cord mean dose, in three studies (Hela et al, Yaparpalvi et al, our study) for mixed beam electron-photon beam technique at three study were highest, but at our study for energy electron $(1,2,3,6,7)$ were lower than other technique (the average is $2 \mathrm{~Gy}$ ) $[8,32$, 33]. As same as resulting Yaparpalvi et al, temporal lobe and temporomandibular joint necrosis is a side-effect of radiotherapy of parotid cancer patient using by all plan and it need to careful attention for treatment while using electron beam and electron-photon mixed beam [8]. All of DVH at figure 3 shown. At our study, the impact of bolus also are considered, but at previous study it just used for photon beam $[8,32,33]$. The resulting of comparison of technique $6,7,8$, 9 showed that the CI was 0.9267 and the HI was approximately 1 for $14 \mathrm{Mev}$ electron, it showed that using of bolus for high energy electron is effective to providing an optimal treatment plan, but for other technique is not improve the treatment plan (table 2,3). Our results shown that presence and absent of bolus are not significantly different, the results of them are significantly similar.

\section{Conclusion}

According to dose distribution, this paper offered using of 3 -field photon with pair wedge technique and electron high energy with using of bolus to achieve optimal treatment plan of parotid cancer. It is noteworthy that when electron beam or mixed beam is used, it would not be good if they accompanied by bolus, because of existing of air gap and the problems of building, design and other problems that mentioned in previous study [27, 30,31]. The techniques 2,6 are not good, because energy beam are low and they could not achieve an optimal treatment plan for parotid tumors. Also use of bolus is dependent to our facilities and would not affect the result.

\section{Acknowledgments}

The authors are grateful for this opportunity provided by Urmia University of medical science and the Omid radiotherapy department 


\section{Conflict of Interest}

The authors declare no conflict of interest.

\section{References}

[1] Johns ME, Goldsmith MM. Incidence, diagnosis, and classification of salivary gland tumors. Part 1. Oncology (Williston Park, NY). 1989; 3 (2): 47-56; discussion, 8, 62.

[2] Halperin EC, Brady LW, Wazer DE, Perez CA. Perez \& Brady's principles and practice of radiation oncology: Lippincott Williams \& Wilkins; 2013.

[3] Foote FW, Frazell EL. Tumors of the major salivary glands: National Academies; 1954.

[4] Tran L, Sadeghi A, Hanson D, Juillard G, Mackintosh R, Calcaterra TC, et al. Major salivary gland tumors: treatment results and prognostic factors. The Laryngoscope. 1986; 96 (10): 1139-44.

[5] Theriault C, Fitzpatrick P. Malignant Parotid Tumors Prognostic Factors and Optimum Treatment. American journal of clinical oncology. 1986; 9 (6): 510-6.

[6] Spiro RH. Salivary neoplasms: Overview of a 35-year experience with 2,807 patients. Head \& neck surgery. 1986; 8 (3): $177-84$

[7] Rafla S. Malignant parotid tumors: natural history and treatment. Cancer. 1977; 40 (1): 136-44.

[8] Yaparpalvi R, Tyerech S, Boselli L, Fontenla D, Beitler J, Vikram B. Parotid gland tumors: a comparison of postoperative radiotherapy techniques using three dimensional (3-D) dose distributions and dose-volume histograms (DVH). International Journal of Radiation Oncology, Biology and Physics. 1996; 36 (1): 393.

[9] Alterio D, Jereczek-Fossa BA, Griseri M, D’Onofrio A, Giugliano G, Fiore MR, et al. Three-dimensional conformal postoperative radiotherapy in patients with parotid tumors: 10 years' experience at the European Institute of Oncology. Tumori. 2011; 97 (3): 328-34.

[10] Kudchadker R, Antolak J, Morrison W, Wong P, Hogstrom K. Utilization of custom electron bolus in head and neck radiotherapy. Journal of Applied Clinical Medical Physics. 2003; 4 (4): 321-33.

[11] Drzymala R, Mohan R, Brewster L, Chu J, Goitein M, Harms $\mathrm{W}$, et al. Dose-volume histograms. International Journal of Radiation Oncology* Biology* Physics. 1991; 21 (1): 71-8.

[12] Grills IS, Yan D, Martinez AA, Vicini FA, Wong JW, Kestin LL. Potential for reduced toxicity and dose escalation in the treatment of inoperable non-small-cell lung cancer: A comparison of intensity-modulated radiation therapy (IMRT), 3D conformal radiation, and elective nodal irradiation. International Journal of Radiation Oncology* Biology* Physics. 2003; 57 (3): 875-90.

[13] Elkon D, Colman M, Hendrickson FR. Radiation therapy in the treatment of malignant salivary gland tumors. Cancer. 1978; 41 (2): 502-6.

[14] Ostwald P, Cooper S, Denham J, Hamilton C. Dosimetry of high energy electron therapy to the parotid region. Radiotherapy and Oncology. 1994; 33 (2): 148-56.
[15] Benoit J, Pruitt AF, Thrall DE. Effect of Wetness Level on the Suitability of Wet Gauze As a Substitute for Superflab ${ }^{\circledR}$ As a Bolus Material for Use With $6 \mathrm{Mv}$ Photons. Veterinary Radiology \& Ultrasound. 2009; 50 (5): 555-9.

[16] Al-Yahya K, Schwartz M, Shenouda G, Verhaegen F, Freeman C, Seuntjens J. Energy modulated electron therapy using a few leaf electron collimator in combination with IMRT and 3DCRT: Monte Carlo-based planning and dosimetric evaluation. Medical physics. 2005; 32 (9): 2976-86.

[17] Luu A, Doerwald-Munoz L, Ostapiak O. An evaluation of two approaches to skin bolus design for patients receiving radiotherapy for head and neck cancers. Journal of Medical Imaging and Radiation Sciences. 2015; 46 (3): S37-S42.

[18] Kong M, Holloway L. An investigation of central axis depth dose distribution perturbation due to an air gap between patient and bolus for electron beams. Australasian Physics \& Engineering Sciences in Medicine. 2007; 30 (2): 111-9.

[19] Günhan B, Kemikler G, Koca A. Determination of surface dose and the effect of bolus to surface dose in electron beams. Medical Dosimetry. 2003; 28 (3): 193-8.

[20] Khan M. The Physics of Radiation Therapy, Lippincott, Williams \& Wilkins. Baltimore, MD. 1994.

[21] Khan FM, Doppke KP, Hogstrom KR, Kutcher GJ, Nath R, Prasad SC, et al. Clinical electron-beam dosimetry: report of AAPM radiation therapy committee task group No. 25. Medical physics. 1991; 18 (1): 73-109.

[22] Butson MJ, Cheung T, Yu P, Metcalfe P. Effects on skin dose from unwanted air gaps under bolus in photon beam radiotherapy. Radiation Measurements. 2000; 32 (3): 201-4.

[23] Kudchadker RJ, Hogstrom KR, Garden AS, McNeese MD, Boyd RA, Antolak JA. Electron conformal radiotherapy using bolus and intensity modulation. International Journal of Radiation Oncology* Biology* Physics. 2002; 53 (4): 102337.

[24] Units ICoR. Fundamental Quantities and Units for Ionizing Radiation: International Commission on Radiation; 1998.

[25] Wambersie A, Landgerg T. ICRU report 62: prescribing, recording and reporting photon beam therapy. International Commission on Radiation Units and Measurements, Bethesda, USA: (supplement to ICRU Report 50). 1999.

[26] Low D, Starkschall G, Bujnowski S, Wang L, Hogstrom K. Electron bolus design for radiotherapy treatment planning: bolus design algorithms. Medical physics. 1992; 19 (1): 11524.

[27] Vyas V, Palmer L, Mudge R, Jiang R, Fleck A, Schaly B, et al. On bolus for megavoltage photon and electron radiation therapy. Medical Dosimetry. 2013; 38 (3): 268-73.

[28] Dobrowsky W, Schlappack O, Kärcher K, Pavelka R, Kment G. Electron beam therapy in treatment of parotid neoplasm. Radiotherapy and Oncology. 1986; 6 (4): 293-9.

[29] Laramore GE, Krall JM, Griffin TW, Duncan W, Richter MP, Saroja KR, et al. Neutron versus photon irradiation for unresectable salivary gland tumors: final report of an RTOGMRC randomized clinical trial. International Journal of Radiation Oncology* Biology* Physics. 1993; 27 (2): 23540. 
[30] Khan Y, Villarreal-Barajas JE, Udowicz M, Sinha R, Muhammad W, Abbasi AN, et al. Clinical and dosimetric implications of air gaps between bolus and skin surface during radiation therapy. Journal of Cancer Therapy. 2013; 4 (7): 1251.

[31] Sharma S, Johnson M. Surface dose perturbation due to air gap between patient and bolus for electron beams. Medical physics. 1993; 20 (2): 377-8.
[32] Helal A, Omar A. Three dimensional conformal postoperative radiotherapy for unilateral parotid gland cancer: A comparison of three different parotid gland irradiation techniques. Alexandria Journal of Medicine. 2013; 49 (4): 379-84.

[33] Nutting christopher M RCG, Cosgrove Vivian P, et al. Optimization of radiotherapy for carcinoma of the parotid gland: a comparsion of conventional, three-dimensional conformal and intensity-modulated technique. radiother oncol. 2001; 60 (2) (163-72). 